\title{
Curly hair-acral keratoderma-caries syndrome
}

INSERM

\section{Source}

INSERM. (1999). Orphanet: an online rare disease and orphan drug data base. Curly hairacral keratoderma-caries syndrome. ORPHA:307766

Curly hair-acral keratoderma-caries syndrome is an extremely rare ectodermal dysplasia syndrome characterized by premature loss of curly, brittle, dry hair, premature loss of teeth due to caries, nail dystrophy with thickening of the finger- and toe-nails, acral keratoderma and hypohidrosis. Additionally, sparse eyebrows and eyelashes, receding frontal hairline and flattened malar region are associated. The severity of features appears to increase with age. 